\title{
Planning of Anti-Disaster Transformer Substation Based on NN and PSO
}

\author{
T. Wang ${ }^{1}$, Q.J. Tang ${ }^{2}$, X.L. Yang ${ }^{2}$, X.D. Liu ${ }^{2}$ \\ ${ }^{1}$ Wenzhou Electric Power Bureau, Wenzhou, China \\ ${ }^{2}$ High Voltage Division, Xi'an Jiaotong University, Xi'an, China \\ Email: liuxuand@mail.xjtu.edu.cn
}

\begin{abstract}
Recently, the frequent extreme natural disasters made enormous damage to the electric grid leading to blackouts. The lifeline system aiming at providing continuous power supply for the important load in extreme natural disasters was designed in that condition. In this paper, a developed model for planning of the transformer substation in lifeline system which considered the effect of existing transformer substations, the motivated areas and punishment areas was proposed. The Hopfield NN was adopted to solve the feeders and the PSO was adopted to new the locations of the transformer substations based on the feeders. The planning result not only took fully use of the existing substation but also get the suitable location for new construction which was satisfactory.
\end{abstract}

Keywords: lifeline system, transformer substation, Hopfield NN, PSO

\section{Introduction}

In recent years, the globe climate became more abnormal [1]. More and more power equipment accidents caused by the natural disasters would lead to the blackouts which affected the normal social activities a lot [2]. Many works have been done to prevent the blackouts from happening. One major research area was focused on finding the more suitable topological structure for power grid to improve the robustness against the disturbance [3]. The other was aimed at improving the secondary controlling and predicting system to minimize the loss when disaster happened [4][5]. All those work improved the reliability of the power grid in some way. However, in 2008, the Wenchuan earthquake in Sichuan province led to almost $31.8 \%$ load shedding which resulted in a loss of about 10.65 billion yuan directly [6]. In the same year, the ice disaster in South China also destroyed over $3600010 \mathrm{kV}+$ transmission lines and $200035 \mathrm{kV}+$ transformer stations which caused large area outage and a great number of economic losses [2]. The frequent blackouts caused by the natural disasters exposed the shortcomings of the defense system that the improvements on the topological structure and secondary system couldn't make up the defect on primary side completely which meant that the strong primary side was necessary [7]. In that context, the State Grid Corporation of China proposed the differentiation construction which included the lifeline system aiming at providing continuous power supply for the important load in extreme natural disasters [8].

As the juncture between the power source and the load, the distribution of the transformer substation determined the structure of the power grid, especially in the lifeline system in which the topological structure was as compact as possible. The problem of distribution planning could be divided into two sub-problems that the substations optimization and feeders optimization [9]. A lot of works had been done to optimize the distribution substation locations [9]-[13]. Masud defined an approach employing linear and integer programming to optimize the capacities and the expansion of the system substation subject to the constraints of cost, load, voltage, and reserve requirements [9]. Crawford used operations research to simultaneously optimize substations and reliability constraints. Thompson made the further research by using the branch and bound model which was utilized a shortest path table to obtain lower bounds and solutions from a transshipment linear programming model for upper bounds [11]. With the development on computer technology, more and more intelligent algorithms were applied in choosing optimal substation location. Xi'an Jiaotong University used the Hopfield neural network (NN) combined with greedy algorithm to find the optimal feeder boundary [14]. Tianjin University and North Electric Power University used the particle swarm optimization (PSO) to find the center in the plane which would be helpful to get the optimal location of the transform substation [15]-[17]. However, almost all 
those works were focused on expanding the power grid system and the building new transformer substation. Little work had been done on how to get the important transform substation in the existing power grid to enhance so that the continuous power supply could be provided to the important load in the extreme disaster. Actually, in the planning of distribution transformer substation, the model was aimed at getting a better economic benefit. Based on that, in this paper, a new kind of improved model considering the effect of environment, the differentiation cost between new construction and reinforce of the existing transformer substation was proposed. The Hopfield NN and PSO were combined in model solution by which no potential substation locations were needed in the calculation process.

\section{The mathematical model}

The planning of the distribution transformer substation aimed at getting best economic benefit. The cost [17] could be divided into two parts that the cost on substation and the cost on transmission line (as shown in equation 1$)$ :

$$
\text { Cost }_{\text {min }}=\text { Cost }_{\text {sub }}+\text { Cost }_{\text {line }}
$$

Here the cost of substation could be seen as follow:

$$
\operatorname{Cost}_{\text {sub }}=\left\{\begin{array}{l}
C_{\text {new }} \frac{r_{0}\left(1+r_{0}\right)^{t}}{\left(1+r_{0}\right)^{t}-1}+S R \quad\left(x_{i}, y_{i}\right) \neq\left(x_{k}, y_{k}\right) \\
C_{\text {exist }} \frac{r_{0}\left(1+r_{0}\right)^{t}}{\left(1+r_{0}\right)^{t}-1}+S R \quad\left(x_{i}, y_{i}\right)=\left(x_{k}, y_{k}\right)
\end{array}\right.
$$

where the $\left(x_{\mathrm{i}}, y_{\mathrm{i}}\right)$ was the coordinate of the transformer substation in the model; the $\left(x_{\mathrm{k}}, y_{\mathrm{k}}\right)$ was the coordinate of the existing transformer substation; the $C_{\text {new }}$ was the cost of new transformer substation construction; $C_{\text {exist }}$ was the cost of existing transformer substation reinforce; $r_{0}$ was the discount rate; $t$ was the depreciable life of the transformer substation.

In that model the effect of existing transformer substations were considered. However, in the lifeline system, it was excepted that the existing transformer substation could be used as fully as possible as the cost of reinforce might had the better economic efficiency than new construction which meant that the $C_{\text {new }}$ was much larger than $C_{\text {exist }}$. But in same special conditions, considering the effect of environment, new construction was necessary sometime as discussed later.

Similarly, the cost of line could be expressed as follow considering the effect of existing transformer substation. To simplify the model, here the effect of existing line was ignored and the distance between substation and load was treated as the straight-line distance on the map.

$$
\text { Cost }_{\text {line }}=\left\{\begin{array}{c}
\sum_{i=1}^{m} \sum_{j=1}^{n} L_{j n e w} \frac{r_{0}\left(1+r_{0}\right)^{l}}{\left(1+r_{0}\right)^{l}-1} d_{i j}+\sum_{i=1}^{m} \sum_{j=1}^{n} \alpha W_{j}^{2} d_{i j} \\
\left(x_{j}, y_{j}\right) \neq\left(x_{k}, y_{k}\right) \\
\sum_{i=1}^{m} \sum_{j=1}^{n} L_{\text {jexist }} \times \frac{r_{0}\left(1+r_{0}\right)^{l}}{\left(1+r_{0}\right)^{l}-1} d_{i j}+\sum_{i=1}^{m} \sum_{j=1}^{n} \alpha W_{j}^{2} d_{i j} \\
\left(x_{j}, y_{j}\right)=\left(x_{k}, y_{k}\right) \\
d_{i j}=\sqrt{\left(x_{i}-x_{i j}\right)^{2}+\left(y_{i}-y_{i j}\right)^{2}} \\
\alpha=\frac{\alpha_{1} \times \alpha_{2} \times \alpha_{3}}{U^{2} \times \cos ^{2} \theta}
\end{array}\right.
$$

where $r_{0}$ was the discount rate; $L_{\text {jnew }}$ was cost of the transmission line construction per unit length; $L_{j e x i s t}$ was cost of the transmission line reinforce per unit length; $l$ was the depreciable life of the transmission on low voltage side; $d_{\mathrm{ij}}$ was the distance between transformer substation $\mathrm{i}$ and load $\mathrm{j}$; $\alpha$ was net loss conversion coefficient; $\alpha_{1}$ was electric energy loss coefficient per unit; $\alpha_{2}$ was the resistance per unit length; $\alpha_{3}$ was the loss hours of the transmission per year; $U$ was the line voltage; $\cos \theta$ was the power factor; $W_{j}$ was the active power of load.

In the lifeline system, the transformer substation was excepted to be far away from the high-risk area, such as the seismic zones, lakes, ice disaster areas and so on. So here two kind of function [16], the $\operatorname{Rew}\left(d_{\mathrm{ik}}\right)$ and the Pun $\left(d_{\mathrm{im}}\right)$, were proposed to improve the objective function. The $\operatorname{Rew}\left(d_{\mathrm{ik}}\right)$ was defined as the motivational factor that encouraged the transformer substation to be built in the suitable area. For example, the suitable area was simplified to a cycle whose center coordinate was $\left(x_{\mathrm{k}}, y_{\mathrm{k}}\right)$ and the radius was $D_{\mathrm{k}}$. It was assumed that the area closer to the center was more suitable to transformer substation construction for that a motivate factor would be added to the objective function while the area outside the suitable cycle added nothing, as shown in equation 6 .

$$
\operatorname{Re} w\left(d_{i k}\right)= \begin{cases}\operatorname{Re} w \times\left(D_{k}-d_{i k}\right)^{2} & D_{k} \geq d_{i k} \\ 0 & D_{k}<d_{i k}\end{cases}
$$

where the Rew was the motivate factor; the $D_{\mathrm{k}}$ was the radius of the cycle; $d_{\mathrm{ik}}$ was the distance between the location $\left(x_{\mathrm{i}}, y_{\mathrm{i}}\right)$ and the center $\left(x_{\mathrm{k}}, y_{\mathrm{k}}\right)$.

Similarly, a punitive function was added to the objection function for those area which was not suitable to transformer substation construction, as shown in equation 7.

$$
\operatorname{Pun}\left(d_{i m}\right)= \begin{cases}\operatorname{Pun} \times\left(D_{m}-d_{i m}\right)^{2} & D_{m} \geq d_{i m} \\ 0 & D_{m}<d_{i m}\end{cases}
$$

Where the Pun was the punitive factor; the $D_{\mathrm{m}}$ was the radius of the cycle; $d_{\mathrm{im}}$ was the distance between the location $\left(x_{\mathrm{i}}, y_{\mathrm{i}}\right)$ and the center $\left(x_{\mathrm{m}}, y_{\mathrm{m}}\right)$.

Based on the discussion above, the developed model could be seen as follow. 


$$
\operatorname{Cost}_{\min }=\operatorname{Cost}_{\text {sub }}+\operatorname{Cost}_{\text {line }}+\sum_{k=1}^{n} \operatorname{Rew}\left(d_{i k}\right)+\sum_{m=1}^{n} \operatorname{Pun}\left(d_{i m}\right)
$$

However, the model was tried to get a better economic efficiency. In other word, the suitable locations of the transformer substation should be found to make the value of Cost $_{\mathrm{min}}$ as small as possible. So, the Rew was negative while the Pun was positive.

\section{The Model Solution with Hopfield NN and PSO}

The problem of planning distribution could be divided into two aspects that the substations optimization and feeders optimization. However, those two aspects were influenced by each other. Based on that condition, the model solution should be divided into two correlative steps, too. In this paper, the feeder optimization was got by Hopfield NN [19] and then the location of transformer substation was got by PSO based on the feeders calculated. The iteration method (as shown in figure 1) was used between those two steps to renew the location of the transformer substation and the feeders. The iteration was begun with a series of random substation coordinate and wouldn't be ended until the location error between the adjacent two calculations was acceptable.

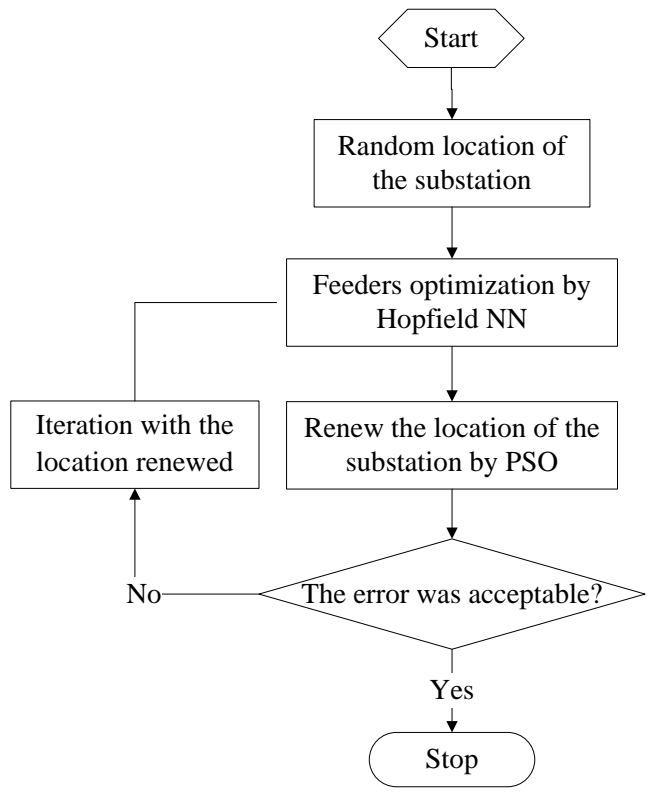

Figure 1. Flow Diagram of Algorithm

As the load capacity of the lifeline system was about 20 percent of the total load capacity, the existing capacity of the transformer substation could meet the requirement of the existing important load. Considering the increase of the load, new transformer substation might be needed whose capacity could be determined base on the capacity-load ratio and the load factor of the transformer as discussed in [16]. The capacity of the substation could be optimized based on the certain location and the feeders.

As shown in equation 8, when the location of the transformer substation was certain, the $\operatorname{Cost}_{\text {sub }} \operatorname{Rew}\left(d_{\mathrm{ik}}\right)$ and $\operatorname{Pun}\left(d_{\text {im }}\right)$ could be calculated which could be treated as a constant $\mathrm{C}$. The Cost $_{\text {line }}$ (as shown in equation 3) could be simplified as following equation.

$$
\text { Cost }_{\text {line }}=\sum_{i=1}^{m} \sum_{j=1}^{n} M_{j}\left(x_{j}, y_{j}\right) d_{i j}
$$

Assumed that one load connected to only one transformer substation, a correspondence among $n$ substation and m loads could be seen in Table 1 .

Table 1. The correspondence among substation and load

\begin{tabular}{ccccc}
\hline & $\mathrm{B}_{1}$ & $\mathrm{~B}_{2}$ & $\cdots$ & $\mathrm{B}_{\mathrm{m}}$ \\
\hline $\mathrm{A}_{1}$ & 1 & 0 & $\cdots$ & 0 \\
\hline $\mathrm{A}_{2}$ & 0 & 1 & $\cdots$ & 0 \\
\hline$\cdots$ & 0 & 0 & $\cdots$ & 1 \\
\hline $\mathrm{A}_{\mathrm{n}}$ & 0 & 0 & $\cdots$ & 0
\end{tabular}

where $A_{i}(i=1,2, \ldots, n)$ was the substation; $B_{i}(i=1,2, \ldots, m)$ was the load; 1 represent the connection; 0 represent the disconnection.

Here, the problem could be described as finding the suitable corresponding connection to get the minimum value of Cost $_{\text {line }}$ which could be solved by a Hopfield NN composed of $n \times m$ units. The value of the units was recorded in the matrix $\mathrm{V}(\mathrm{n}, \mathrm{m})$. An energy function was defined considering the equation 9 and the constraint of the substation capacity [14][18].

$$
\begin{aligned}
E= & \frac{A}{2} \sum_{\mathrm{j}=1}^{m}\left(\sum_{\mathrm{i}=1}^{n} V_{i j}-1^{2}+\frac{B}{2} \sum_{\mathrm{j}=1}^{m} \sum_{i=1}^{n} M_{j} d_{i j} V_{i j}\right. \\
& +\frac{C}{2} \sum_{i=1}^{n}\left(\frac{1}{1+\mathrm{e}^{-\Delta S_{i} / U_{s}}}-1\right)^{2}
\end{aligned}
$$

where the $V_{\mathrm{ij}}$ was the element in matrix $\mathrm{V}(\mathrm{n}, \mathrm{m})$; $\Delta S_{i}=S_{i}-\sum_{j=1}^{n} W_{j} V_{i j}$ respect the constraint of the substation; $U_{s} \leq 0.001 \times W_{j \min } ; \mathrm{A}, \mathrm{B}, \mathrm{C}$ was the weight coefficients.

Taking the derivation of equation 10, the dynamical function of the Hopfield NN was got as follow [14][18].

$$
\begin{aligned}
\frac{d u_{i j}}{d t} & =-\frac{\partial E}{\partial V_{i j}}=-A\left(\sum_{\mathrm{i}=1}^{n} V_{i j}-1-\frac{B}{2} M_{j} d_{i j}\right. \\
& +C \sum_{i=1}^{n}\left(\frac{1}{1+\mathrm{e}^{-\Delta S_{i} / U_{s}}}-1\right) \frac{\mathrm{e}^{-\Delta S_{i} / U_{s}} W_{j}}{u_{s}\left(1+\mathrm{e}^{-\Delta S_{i} / U_{s}}\right)^{2}}
\end{aligned}
$$


Owning to the characters of the Hopfield NN, the energy function would be monotone decreasing until got constant as the dynamical function kept less than or equal to zero. When the calculation was finished, an normalization was adopt to every line of the matrix $\mathrm{V}(\mathrm{n}, \mathrm{m})$ so that only one element was one while others kept zero which meant that the connection relation among transformer substations and loads were certain.

The location of the transformer substation would be renewed aiming at finding a suitable coordinate to get the minimum value of the Cost ${ }_{\text {min }}$ (as shown in equation 8) based on the certain feeders. However, the differentiation of land status in this model made it hard to get the suitable coordinate with the traditional analytic method. As the superiority in the extremum problem, PSO arithmetic was used in model solution. Considering the effect of the existing transformer substation, the initial particle swarm was constituted of the location of the existing transformer substation and the random coordinate in the planning area. During the calculation process, the particle swarm would be renewed based on the group extremum and the individual extremums got by iteration. A mutation (Genetic Algorithm) was used on the new particle swarm every time to prevent local optimum occurring.

\section{Simulation example}

In this section, then loads was used to examine the planning method discussed before. The date for simulation, for example, the capacity of the existing transformer substation and the loads, the cost for substation and line construction, the maintenance charge, was set based on statistics of wenzhou power network. All the coordinates used in the simulation were uniformization. The location of the load could be seen in Table 2. The location of two transformer substation were $(0.1,0.2)$ and $(0.4,0.6)$. Using the Hopfield $N N$ to get the feeders, the result was shown in Figure 2.

The path length in Figure 2 was 10 totally. Then, the Hopfield NN and the PSO was combined to get the final location of the substation and the feeders. Considering the effect of the environment and the existing transformer substation, two punishment area, two existing substation and one motivated area was defined here as seen in Table 3 . The result could be seen in Figure 3.

Table 2. The coordinates of the loads

\begin{tabular}{ccccccccccc}
\hline & $\mathrm{L}_{1}$ & $\mathrm{~L}_{2}$ & $\mathrm{~L}_{3}$ & $\mathrm{~L}_{4}$ & $\mathrm{~L}_{5}$ & $\mathrm{~L}_{6}$ & $\mathrm{~L}_{7}$ & $\mathrm{~L}_{8}$ & $\mathrm{~L}_{9}$ & $\mathrm{~L}_{10}$ \\
\hline $\mathrm{x}$ & 0.1 & 0.2 & 0.4 & 0.5 & 0.7 & 0.8 & 0.2 & 0.5 & 0.7 & 0.9 \\
\hline $\mathrm{y}$ & 0.6 & 0.3 & 0.1 & 0.5 & 0.2 & 0.4 & 0.8 & 0.9 & 0.6 & 0.8 \\
\hline
\end{tabular}

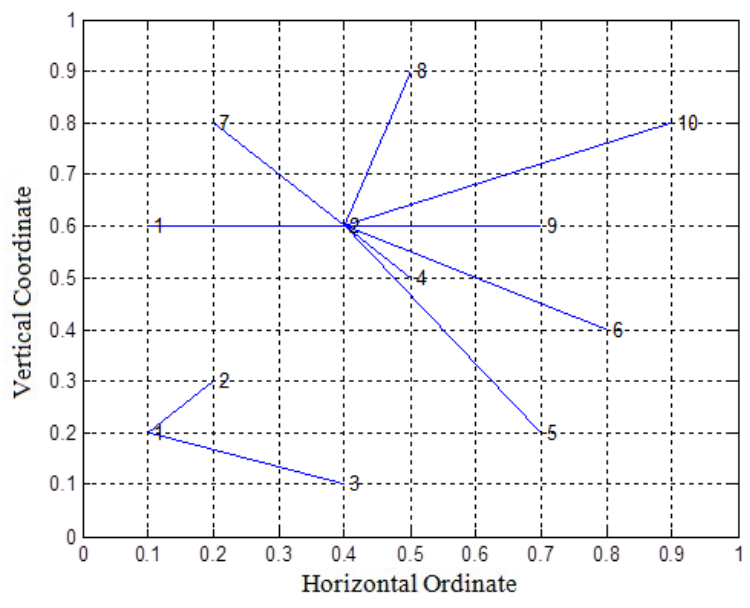

Figure 2. The feeders calculated by Hopfield NN

Table 3. The correspondence among substation and load

\begin{tabular}{cccc}
\hline & Center & Radius & location \\
\hline Punishment area 1 & $(0.55,0.50)$ & 0.2 & $/$ \\
\hline Punishment area 2 & $(0.60,0.70)$ & 0.2 & $/$ \\
\hline Motivated area 1 & $(0.30,0.0 .20)$ & 0.1 & $/$ \\
\hline Motivated area 2 & $(0.80,0.65)$ & 0.1 & $/$ \\
\hline Existing substation & $/$ & $/$ & $(0.30,0.55)$ \\
\hline
\end{tabular}

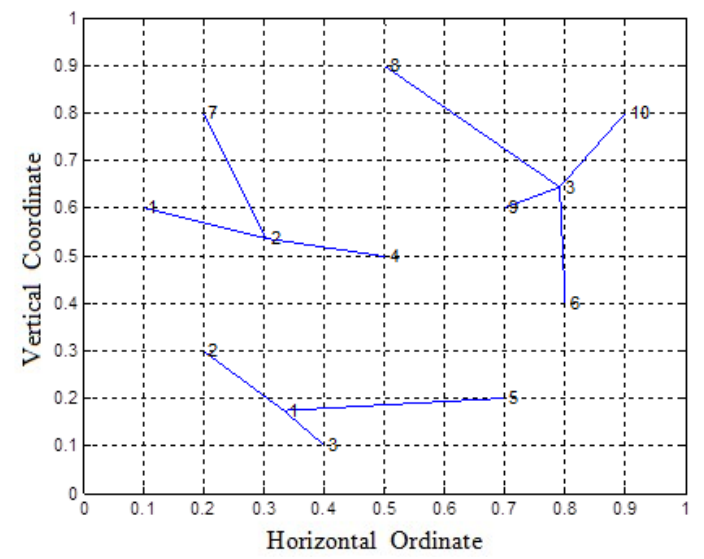

Figure 3. The planning considering the effect of environment and existing transformer substation

The final location of the transformer substations were $(0.33,0.17),(0.30,0.54)$ and $(0.79,0.64)$ which were far away from the punishment areas. In Figure 3, it could been seen that substation 2 almost had the same location to the existing substation and the other two substations were very close to the center of the motivated areas.

\section{Conclusion}

In this paper, a developed model for planning of the 
transformer substation in lifeline system was proposed. In the lifeline system, it was excepted that the existing transformer substation could be used as fully as possible to get the better economic efficiency. So in this model, the effect of existing transformer substations, the motivated areas and punishment areas were considered. To solve the model, the Hopfield NN was adopted to solve the feeders and the PSO was adopted to new the locations of the transformer substations based on the feeders. The iteration method was used between those two steps. By the model and the corresponding algorithm, the planning of transformer substation not only took fully use of the existing substation but also get the suitable location for new construction, which was satisfactory

\section{REFERENCES}

[1] Q. Xie and J. Li, "Current situation of natural disaster in electric power system and countermeasures," Journal of Natural Disasters, Vol. 15, No. 4, 2006, pp. 126-131.

[2] AMIN.M, "Toward self-healing energy infrastructure systems," IEEE Computer Applications in Power, VOL. 14, NO. 1, 2001, pp: 20-29.

[3] S.Blumsack. "Defining Power Network Zones from Measures of Electrical Distance," Conference Record of the IEEE Power \& Society General Meeting, 2009, pp: $1-8$.

[4] Y.S. Xue. "Space-time cooperative framework for defending blackouts: Part II reliable information, quantitative analyses and adaptive controls," Electric Power System, 2006, VOL. 30, NO. 2, pp: 1-10.

[5] Y.S. Xue. "Quantitative study of general motion stability and an example on power system stability," Jiangsu Science and Technology Press, 1999.

[6] X.H. Zhang, G.N. Wu, etc. "Effects of Wenchuan Earthquake on Sichuan Grid," Modern Electric Power, 2009, VOL. 26, NO. 4, pp: 4-9.

[7] Y.S. Xue, S.Y. Fei, etc. "The Blackouts Defense System in Extreme Disaster Part I new challenge and introspection," Automation of Electric Power System, 2008, VOL. 32, NO. 9, pp: 1-6.
[8] M. Lu, D.H. Hu, etc. "Consideration of Strong \& Smart Grid,” Central China Electric Power, 2010, VOL. 12, NO. 6, pp: 1-7.

[9] Enver Masud. “An Interactive Procedure for Sizing and Timing Distribution Substations Using Optimization Techniques," IEEE Power System, 1973, VOL. PAS-93, NO. 5, pp: 1281-1285.

[10] D.I. Sun, D.R. Farris, etc. "Optimal Distribution Substation and Primary Feeder Planning via the Fixed Charge Network Formulation," IEEE Transactions on Power Apparatus and Systems, 1982, VOL. PAS-101, NO. 3, pp: 602-609.

[11] D.M Cowford. “A Mathematical Optimization Technique for Locating and Sizing Distribution Substations and Deriding Their Opitmal Service," IEEE Transaction on Power Apparatus and Systems, 1975, VOL. 94, NO. 2, pp: 230-235.

[12] G.L. Thompson. "A Branch and Bound Model for Choosing Optimal Substation Location," IEEE Transactions on Power Apparatus and Systems, 1981, VOL. 100, NO. 5, pp: 2683-2688.

[13] T.H. Fawzi, K.F. Ali, etc. "A New Planning Model for Distribution Systems," IEEE Transactions on Power Apparatus and Systems, 1983, VOL. PAS-102, NO. 9, pp: 3010-3017.

[14] W.X. Gao, X.J. Luo, etc. “A New Distribution Substation Planning Algorithm Based on Greedy Algorithm and Hopfield Neural Network," Power System Technology, 2004, VOL. 28, NO. 7, pp: 73-76.

[15] T. Zeng. "Research on Substation Planning Based on Particle Swarm of Culture Algorithm," Tianjin University, 2008.

[16] Y.W. Zhang. "Optimal Planning for Substation Locating and Sizing,” Tianjin University, 2005

[17] H.W. Dai. "Optimal Planning of Distribution Substation Location and Sizes-model and Algorithm,” International Journal of Electrical Power and Energy System, 1996, VOL. 18, NO. 6, pp: 353-357.

[18] F.Shi, X.C. Wang, etc. "30 cases analysis of Matlab Neural Network," The Beijing University of Aeronautics and Astronautics Press, 2010. 